\title{
REMOTE SENSING IN A CHANGING CLIMATE AND ENVIRONMENT: THE RIFT VALLEY FEVER CASE
}

\author{
Y. M. Tourre ${ }^{\mathrm{a}}$ J.-P. Lacaux ${ }^{\mathrm{b}}$, C. Vignolles ${ }^{\mathrm{c}}$, and M. Lafaye ${ }^{\mathrm{c}}$ \\ ${ }^{a}$ Meteo-France and Lamont-Doherty of Columbia University, Palisades, 10964, NY (yvestourre@aol.com) \\ ${ }^{\mathrm{b}}$ CNRS/OMP, Laboratoire d'Aérologie, Toulouse, France (lacjp@aero.obs-mip.fr) \\ ${ }^{c}$ Centre National d'Etudes Spatiales (CNES), Toulouse, France (cecil.vignolles@cnes.fr, \\ murielle.lafaye@cnes.fr)
}

Commission VIII, WG VIII/2 Health

Keywords: Climate change, Public health, Remote sensing, Risk mapping, Infectious diseases, Early warning systems

\begin{abstract}
Climate and environment are changing rapidly whilst global population already reached 7 billions people. New public health challenges are posed by new and re-emerging diseases. Innovation is a must i.e., 1) using high resolution remote sensing, 2) re-invent health politics and trans-disciplinary management. The above are part of the 'TransCube Approach' i.e., Transition, Translation, and Transformation. The new concept of Tele-epidemiology includes such approach. A conceptual approach (CA) associated with Rift Valley Fever (RVF) epidemics in Senegal is presented. Ponds are detected using high-resolution SPOT-5 satellite images and radar data from space. Data on rainfall events obtained from the Tropical Rainfall Measuring Mission (NASA/JAXA) are combined with in-situ data. Localization of vulnerable and parked hosts (obtained from QuickBird satellite) is also used. The dynamic spatio-temporal distribution and aggressiveness of RVF mosquitoes, are based on total rainfall amounts, ponds' dynamics and entomological observations. Detailed risks maps (hazards + vulnerability) in real-time are expressed in percentages of parks where animals are potentially at risks. This CA which simply relies upon rainfall distribution from space, is meant to contribute to the implementation of the RVF early warning system (RVFews). It is meant to be applied to other diseases and elsewhere. This is particularly true in new places where new vectors have been rapidly adapting (such as Aedes albopictus) whilst viruses (such as West Nile and Chikungunya,) circulate from constantly moving reservoirs and increasing population.
\end{abstract}

\section{INTRODUCTION}

\section{The Varying Climate}

Climate changes and varies at all time scales. Natural climate signals fluctuations have been identified from the diurnal, to multi-decadal (MD) periods along with seasonal, quasi-biennial (QB), El-Niño-Southern Oscillation (ENSO), quasi-decadal (QD) and interdecadal (ID) oscillations at least (Tourre and White, 2006). Adding to these fluctuations is the anthropogenic component, from population increase and energetic needs. All fluctuations are interacting, with direct impacts on public health.

\section{Climate Variability and Public Health}

Climate variability and change bring global inequalities (Plan Bleu, 2008) associated with economic migration (enhancing that from political turmoil). Changes have been observed in nutrient budget, virus and bacteria circulation, all impacting public health. Total primary energy demand is expected to increase by $\sim 60 \%$ during the first quarter of the 21 st century. Socio-economical chaos should have impacts on the environment and public health i.e., infectious diseases, respiratory and circulatory problems, pollution, allergens, impaired immune systems, new and re-emerging diseases. Health issues are also associated with poor water quality and malnutrition. Most emerging (or re-emerging) infectious diseases are due partly to the introduction of new pathogenic agents from wildlife into new and unprepared population, thus creating new hazards and risks. Processes may depend upon, sanitation levels, and/or breakdowns in health information systems (HIS).

\section{Climate Variability and Infectious Diseases}

Almost $75 \%$ of actual infectious diseases in humans are zoonoses. The last quarter of the 20th century has witnessed an explosion of environmentally-related illnesses. For infectious diseases, this includes increases in the prevalence, incidence and geographical distribution across wide taxonomic ranges, related to climate/environment changes and practical changes in land-use.

Direct health effects of climate variability include: changes in morbidity and mortality from heat-waves and thermal stress (such as in 2003 over southwest Europe; in 2007 over Italy and Greece); respiratory ailments associated with modified concentrations of aero-allergens (spores, moulds, fungus) and/or air pollutants; health consequences from extreme weather events, including storms, cold waves, floods, storm surges, droughts, windstorms, among others. Indirect health effects, include alterations in the ecology, range and activity of vector-borne infectious diseases (i.e., Malaria, West Nile Virus from Africa to USA, Rift Valley Fever from Kenya to Senegal and Mauritania, Avian Flu, Chikungunya from the Indian Ocean to southern France and northern Italy, Dengue Fever from central America to Florida, New 
Orleans, Texas, among others) (Takken, 2006); alterations in the environment of water-borne diseases and pathogens (i.e., gastro-intestinal infections, Vibrios diseases including Cholera); alterations in the atmospheric boundary layer, and transmission of airborne diseases (Meningococcal meningitis, respiratory ailments); alterations and regional changes in agricultural practices and food security (malnutrition, lack of fresh water).

\section{Climate/Environmental Variability and Remote Sensing}

Public health indicators and disease surveillance activities should be integrated with other in-situ observing systems such as Global Climate Observing System (GCOS), Global Ocean Observing System (GOOS), Global Terrestrial Observing System (GTOS), and Global Earth Observation System of Systems (GEOSS). Today, the use of satellites allows monitoring changes in environmental and climatic parameters at high resolution. The example and the detailed and integrated conceptual approach (CA) of Tele-epidemiology for the Rift Valley Fever (RVF) are given hereafter.

\section{DECISION MAKING and 'TRANSCUBE CONCEPT'}

1. Climate Variability and Decision Making

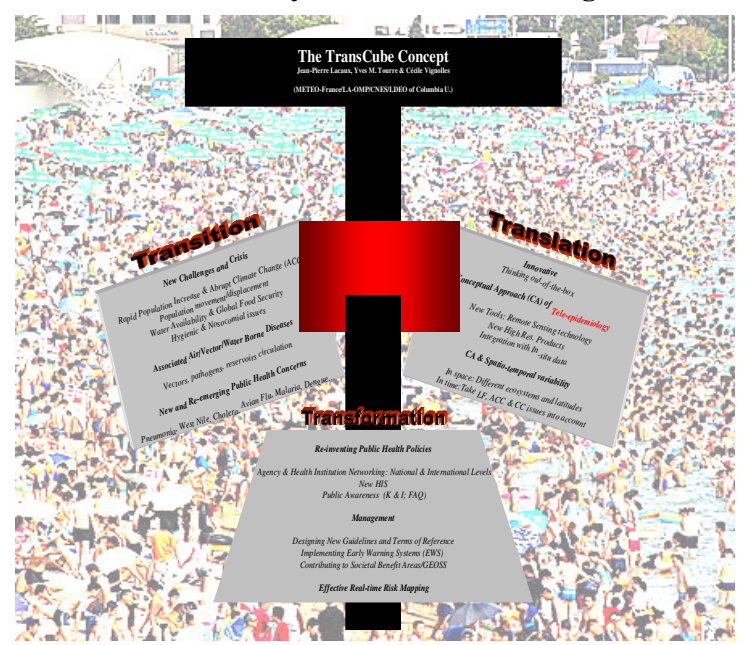

Climate variability affects regional socio-economical cost/loss, reflecting the local balance/imbalance from temperature and soil moisture changes, use and abuse of fertilizers, pest and pathogens activity. Decision-making models used are thus to include

1. Identification of "normal" impacts of disease (in lives and Euros).

2. Definition of a "climate event" linked to a "health event" (epidemics, endemics, pandemics...).

3. Definition of "increased impacts" and losses (in lives and Euros).

4. Identification of effective methods to mitigate losses.

5. Definition of costs (Euros) for implementation of the above and improve HIS.

6. Quantification of the savings (in lives and Euros) if a "health event" does not occur?

\section{The 'TransCube Concept'}

Some epidemics are emerging or re-emerging all over the world. The integrated and trans-disciplinary 'TransCube Concept' presented for the first time at World Health Summit (Berlin, 2010) is being applied here and includes the Tele-epidemiology approach (see Figure to the left). It consists of three phases, namely the:

1) Transition phase: Coping with new challenges from new and re-emerging diseases;

2) Translation phase: Innovating beyond benches and bedsides by using high res. Technology (including optical and radar remote sensing);

3) Transformation: Re-inventing public health politics, managerial and security issues, including new guidelines and terms of references (TORs) in a climate variability and change context, to be applied to effective early warning systems (EWS).

Forecasting climate impacts on public health requires the development of scenario-based risks (i.e., hazards + vulnerability) assessments which must include consequences from demographic, social, political and economical disruptions. Integrated mathematical modelling must be used (Martens, 2001) requiring all components of the chain of causation (each step being a link of the TransCube Approach).

\section{Tele-epidemiology}

The new conceptual approach of Tele-epidemiology has been put into action (Lafaye, 2006). It is to monitor and study the spread of human and animal infectious diseases which are closely tied to climate and environmental variability evaluated from space. By combining satelliteoriginated data on vegetation (SPOT-image), meteorology (Meteosat, TRMM), oceanography (Topex/Poseidon; ENVISAT, JASON) with hydrology data (distribution of water bodies), with clinical data from humans and animals, entomological data, predictive mathematical models can be constructed.

\section{THE RIFT VALLEY FEVER (RVF) CASE}

The various components of the above approach have been thoroughly tested with the RVF in the Ferlo (Senegal). This successful approach has lead the Senegalese government to provide funding, and extend the approach in places where populations and cattle are exposed (Vignolles et al., 2009).

The Ferlo region in Senegal, became prone to RVF in the late $1980 \mathrm{~s}$ with the appearance of infected vector/mosquitoes from the Aedes vexans and Culex poicilipes species (Lacaux et al., 2007; Tourre et al., 2008) near temporary ponds. RVF epizootic outbreaks in livestock cause spontaneous abortions and perinatal mortality. So far, human-related disease symptoms may include severe forms of encephalitis and hemorrhagic fevers.

The ultimate goal has been to use specific Geographical Information System (GIS) tools (Tourre et al., 2007) and high resolution remote sensing images/data to detect the "beating" of the breeding ponds and evaluate areas at 
risks: the so-called Zone Potentially Occupied by Mosquitoes (ZPOM).

The integrated approach to determine the environmental risk levels of RVF (CNES, 2008) bridges the physical and biological mechanisms, linking environmental conditions to the production of RVF vectors and the accompanying potential risks.

Possible hazards in the vicinity of fenced-in hosts are displayed in the second Figure, where the mapped ZPOM is displayed. In the Figure the Zone Potentially Occupied by Mosquitoes, or ZPOMs with ranked hazards from yellow (low hazards) to red (high hazards). ZPOM in the Barkedji area (large black area) is obtained from the ponds distribution after a single rainfall event (top left). Localization of the Barkedji village and ruminants' fenced-in areas (vulnerability, from QuickBird) in black for the same area (top right). Potential risks i.e., = hazards + vulnerability are shown by super-imposing the two pictures (bottom of Figure).

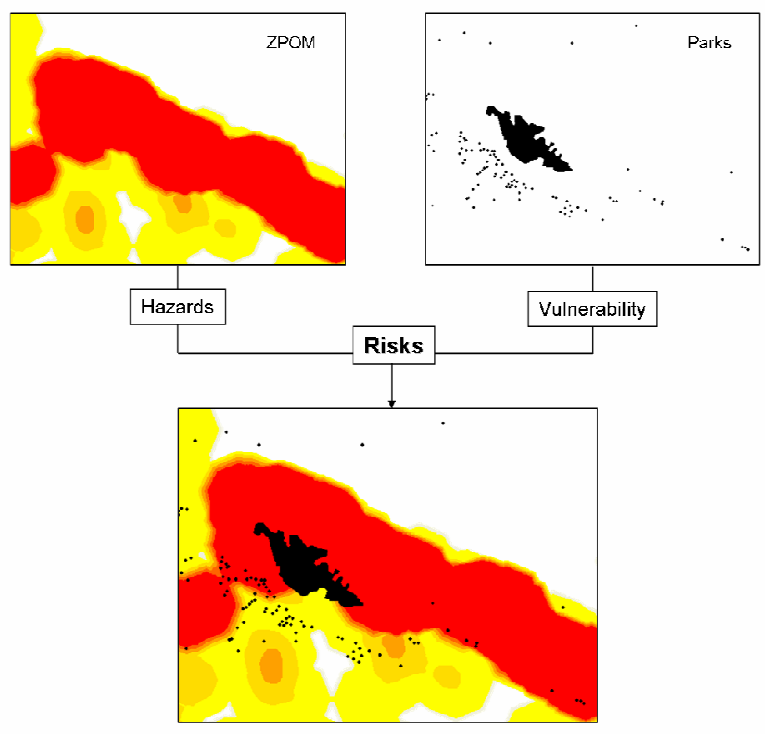

\section{CONCLUSIONS}

Climate variability and change and environmental risks comprise mechanisms linking rainfall variability and trends, density of vectors/mosquitoes and their aggressiveness, and hosts vulnerability. The dynamical evolution of ZPOMs, from ponds clustering, has identified risks as a function of discrete and productive rainfall events. The socio-economic risks can thus be anticipated based on statistical evaluation of the seasonal rainfalls which can be done a few months prior to the rainy season (based upon seasonal forecasts).

Impacts mitigation can be accomplished though strategic displacement of the fenced-in animals during the course of the rainy season, vaccination, destruction of vectors. The Transcube Model and the conceptual approach presented here are to be linked with biological modelling of virus transmission and circulation, as well as with classical epidemiological models. Ultimately, the fully integrated approach should help understanding the mechanisms leading to potential RVF epidemics and improve related EWS or "RVFews".

The physical and biological mechanisms from other infectious diseases are to be developed by applying a similar methodology elsewhere (including higher-latitude regions) where climate and environment are also varying and changing rapidly. This is in the process of being implemented for Malaria epidemics over Burkina Faso (PaluClim project).

\section{REFERENCES}

CNES, 2008 : Method for tele-epidemiology (Méthode pour la télé-épidémiologie). Patent pending \# PCT/FR2009/050735.

Lacaux J-P., Tourre Y. M., Vignolles C., Ndione J-A., Lafaye M., 2007 : Classification of ponds from high spatial resolution remote sensing: application to rift valley fever epidemics in Senegal. J. Remote Sensing Env., 106, 66-74.

Lafaye M., 2006 : Nouvelles applications spatiales pour la santé: la télé-épidémiologie pour le suivi des fièvres aviaires. CNES Magazine, February, 30-31.

Martens, P. 2001: Climate Change: Vulnerability and Sustainability. IPCC TAR report. www.grida.no/climate/ipcc_tar/wg2/539.htm

Plan Bleu, 2008 : Mediterranean Basin: Climate Change and Impacts during the 21st century. Report 2008, Le Plan Bleu, Sophia Antipolis, 15 Rue Beethoven, 06560, pp 67.

Takken, W., 2006 : Environmental Change and Malaria Risk: Global and Local Implications. Springer Edit. pp150. ISBN-13: 978-1402039270.

Tourre Y. M., White W. B., 2006 : Global climate signals and equatorial SST variability in the Indian, Pacific and Atlantic oceans during the 20th century. Geophys. Res. Lett., 33, L06716, doi: 10.1029/2005GL025176.

Tourre Y. M., Fontannaz D., Vignolles C., Ndione J-A., Lacaux J-P., Lafaye M., 2007 : GIS and high-resolution remote sensing improve early warning planning for mosquito-borne epidemics. Healthy GIS, GIS for Health and Human Services, ESRI, 1-4.

Tourre Y.M., Lacaux J-P., Vignolles C., Ndione J-A., Lafaye M., 2008 : Mapping of zones potentially occupied by Aedes vexans and Culex poicilipes mosquitoes, the main vectors of Rift Valley Fever in Senegal. Geospatial Health 3 (1), 69-79.

Vignolles C., Lacaux J-P., Tourre Y. M., Bigeard G., Ndione J-A., Lafaye M., 2009 : Rift Valley fever in a zone potentially occupied by Aedes vexans in Senegal: dynamics and risk mapping. Geospatial Health 3 (2), 211-220. 
International Archives of the Photogrammetry, Remote Sensing and Spatial Information Sciences, Volume XXXIX-B8, 2012 XXII ISPRS Congress, 25 August - 01 September 2012, Melbourne, Australia

\section{ACKNOWLEDGEMENTS}

Our research is funded through the "Gestion des Impacts du Changement Climatique (GICC)", a program supported by the French "Ministère de l'Ecologie, du Développement Durable, des Transports et du Logement (MEDDTL)". The authors would like also to thank Dr. Antonio Güell, Head of the Application and Valorization department at CNES. Tourre would like to thank Dr. Philippe Dandin, Director of the Climatology department at Méteo-France and Dr. Mike Purdy recently appointed Columbia University's Executive Vice President for Research, for facilitating this applied research. 